\title{
La-doped and La/Mn-co-doped Barium Titanate Ceramics
}

\author{
M.M. Vijatović Petrovićc ${ }^{a, *}$, J.D. Bobić ${ }^{a}$, R. Grigalaitis ${ }^{b}$, B.D. Stojanović ${ }^{a}$ \\ AND J. BANYS ${ }^{b}$ \\ ${ }^{a}$ Institute for Multidisciplinary Research, University of Belgrade, Kneza Višeslava 1, Belgrade, Serbia \\ ${ }^{b}$ Faculty of Physics, Vilnius University, Sauletekio al. 9, Vilnius, Lithuania
}

(Received November 27, 2012; in final form March 27, 2013)

\begin{abstract}
Barium titanate ceramics doped with 0.3 mol.\% lanthanum and co-doped with 0.3 mol.\% lanthanum and $0.05 \mathrm{~mol} . \%$ manganese were investigated. The powders were prepared by a modified polymeric precursor method based on the Pechini process. The ceramics were obtained by sintering at $1300{ }^{\circ} \mathrm{C}$ for $8 \mathrm{~h}$. The influence of dopants on structural changes and grain size reduction was analyzed. The presence of dopants influenced the tetragonality of the barium titanate crystal structure. Reduction of polygonal grain size with dopant addition was noticed. In the doped ceramics, characteristic phase transitions were shifted to lower temperatures in comparison with pure barium titanate. The dielectric permittivity value showed the tendency of a slight increase with lanthanum addition and further increase with adding of manganese. La as a single dopant increased the diffuseness of phase transitions indicating the formation of a diffuse ferroelectric material but in the co-doped ceramics the phase transition diffuseness decreased. The resistivity of the co-doped ceramics was higher than for lanthanum doped ceramics, indicating possible segregation of manganese at grain boundaries that influenced the total resistivity of the material.
\end{abstract}

DOI: $10.12693 /$ APhysPolA.124.155

PACS: 81.20.Ka, 81.40.Ef, 77.80.B-, 72.20.-i, 84.37.+q

\section{Introduction}

Over the years barium titanate $\left(\mathrm{BaTiO}_{3}, \mathrm{BT}\right)$ has been exceedingly investigated due to its very interesting practical applications in capacitors, thermistors, varistors, energy converting systems etc. The perovskite structure of barium titanate $\left(\mathrm{ABO}_{3}\right)$ has the capability to host different sized ions and the properties of this material could be tailored by doping. Doping is possible at both A and $\mathrm{B}$ sites and it depends on the valence and radius of the substituting ions [1]. The barium titanate crystal structure, microstructure and dielectric properties could be changed by incorporation of very low concentrations of dopants into its lattice. Some dopants shift BT transition temperatures or induce broadening of the $\varepsilon-T$ curve and many of them cause diffuseness of the ferroelectric phase transition $[2,3]$. The degree of diffuseness of the phase transition could show a continuous change from classical ferroelectric to diffuse ferroelectric or to relaxor, depending on the type and concentration of dopant incorporated in the BT lattice.

Lanthanum as a donor dopant commonly substitutes $\mathrm{Ba}$ in the lattice of barium titanate. Since $\mathrm{La}^{3+}$ has a different valence than $\mathrm{Ba}^{2+}$ this change produces a charge imbalance and induces $n$-type semiconductivity. Therefore, charge compensation requires the production of electrons, electron holes or titanium $\left(\mathrm{V}_{\mathrm{Ti}}\right)$ and oxygen $\left(\mathrm{V}_{\mathrm{O}}\right)$ vacancies in the material, causing modification of electrical properties. On the other hand, manganese is

*corresponding author; e-mail: miravijat@yahoo.com believed to substitute $\mathrm{Ti}^{4+}$ and acts as an acceptor with unstable valence, from $\mathrm{Mn}^{2+}, \mathrm{Mn}^{3+}$ to $\mathrm{Mn}^{4+}$ depending on the oxygen partial pressure [4]. Some theoretical and experimental studies have been done on the valence of manganese that could exist in the BT lattice [5-7]. In a reducing atmosphere $\mathrm{Mn}^{2+}$ is likely to be found but it converts into $\mathrm{Mn}^{4+}$ in oxidizing conditions [5]. In air processed samples Schwartz et al. found both $\mathrm{Mn}^{2+}$ and $\mathrm{Mn}^{4+}$ with no traces of $\mathrm{Mn}^{3+}$. Usually manganese acts as an acceptor-type impurity at the grain boundaries. For co-doped systems the formation of donor-acceptor complexes, such as $2\left[\mathrm{LaBa}^{\bullet}\right]-\left[\mathrm{MnTi}^{\prime \prime}\right]$ prevents a valence change of $\mathrm{Mn}^{2+}$ to $\mathrm{Mn}^{3+}$ and has a beneficial effect on reduction of the dissipation factor. Formation of the same complexes was also found in cases of co-doping of BT with $\mathrm{W} / \mathrm{Mn}$ and $\mathrm{Nb} / \mathrm{Mn}$ [7].

In this paper, the focus was on determining the roles of an individual dopant, La and joint effects of two dopants, $\mathrm{La} / \mathrm{Mn}$ on the properties of $\mathrm{BaTiO}_{3}$ ceramics that have shown very interesting behavior. The crystal structure change and a correlation between microstructure development and dielectric properties of the obtained doped ceramics are reported.

\section{Experimental}

A modified Pechini process was used to prepare nanopowders of barium titanate doped with $0.3 \mathrm{~mol} . \%$ of lanthanum (BTL) and barium titanate doped with $0.3 \mathrm{~mol} . \%$ of lanthanum and $0.05 \mathrm{~mol} . \%$ of manganese (BTLM). Barium acetate $\left(\mathrm{Ba}\left(\mathrm{CH}_{3} \mathrm{COO}\right)_{2}\right)$, Alfa Aesar, 99.0-102.0\%), titanium iso-propoxide ( $\mathrm{Ti}$ $\left[\mathrm{OCH}\left(\mathrm{CH}_{3}\right)_{2}\right]_{4}$, Alfa Aesar, 99.995\%), lanthanum nitrate $\left(\mathrm{La}\left(\mathrm{NO}_{3}\right)_{3} \cdot 6 \mathrm{H}_{2} \mathrm{O}\right.$, Alfa Aesar, 99.99\%) and manganese 
oxide $\left(\mathrm{MnO}_{2}\right.$, Merck, 99.8\%) were used as starting materials. Solutions of titanium citrate and barium citrate were prepared using ethylene glycol (EG) and citric acid (CA) as solvents (M (metal ion): $\mathrm{CA}: \mathrm{EG}=1: 4: 16)$. After mixing of the obtained citrate solutions lanthanum nitrate salt and manganese oxide were added. The transparent yellow solution was heated up to $140^{\circ} \mathrm{C}$ until it changed to a dark-brown glassy resin. Decomposition of organic resin was performed at $250{ }^{\circ} \mathrm{C}$ for $1 \mathrm{~h}$ and $300^{\circ} \mathrm{C}$ for $4 \mathrm{~h}$, when a black solid mass was formed. Thermal treatment of the formed precursor was performed at $500^{\circ} \mathrm{C} / 4 \mathrm{~h}, 700^{\circ} \mathrm{C} / 4 \mathrm{~h}, 800^{\circ} \mathrm{C} / 2 \mathrm{~h}$ and $850^{\circ} \mathrm{C} / 2 \mathrm{~h}[8,9]$.

Nanopowders were uniaxially pressed into disks $12 \mathrm{~mm}$ in diameter at a pressure of $196 \mathrm{MPa}$. Sintering was performed in air at $1300{ }^{\circ} \mathrm{C}$ for $8 \mathrm{~h}$ with a heating rate of $10^{\circ} \mathrm{C} / \mathrm{min}$.

$\mathrm{X}$-ray diffraction measurements were carried out in order to determine the formed crystal structure and lattice parameters (Philips PW1710 diffractometer). Scanning electron microscopy (Tescan VEGA TS 5130MM) was used to analyze the microstructure of obtained ceramics. Average grain size was determined from scanning electron microscopy (SEM) micrographs using linear intercept technique. The density of barium titanate ceramics was calculated geometrically. Samples were prepared for electrical measurements by polishing and applying silver electrodes on both sides of the samples. Dielectric measurements were carried out using a LCR meter (model 4284 A, Hewlett-Packard).

Impedance measurements of BTLM ceramics were carried out at $500{ }^{\circ} \mathrm{C}$ in the frequency range $42 \mathrm{~Hz}-5 \mathrm{MHz}$ using a HIOKI 3532-50 LCR HiTester. To obtain continuous metallic contacts, Pt paste was deposited on the polished surfaces of the ceramics. Collected data were analyzed using the commercial software package $Z$-view.

\section{Results and discussion}

Barium titanate pure and doped nanopowders with round shaped particles $\approx 50-70 \mathrm{~nm}$ were prepared by a soft chemical method, a modified Pechini process [3]. Synthesized powders were used to prepare ceramic samples by pressing into pellets. In accordance with previous results sintering was performed at $1300{ }^{\circ} \mathrm{C}$ for $8 \mathrm{~h}[3]$.

$\mathrm{X}$-ray diffraction measurements (Fig. 1) showed formation of a tetragonal crystal structure in barium titanate ceramics identified by the appearance of characteristic diffraction peaks (JCPDS files no. 05-0626). Lattice parameters were calculated using the "Lsucri" program and a crystal structure change was evident. The tetragonality $(c / a)$ of the BTL ceramic was 1.0102, while for BTLM it was lower than 1.0078. The decrease of tetragonality noticed after addition of dopants suggested the formation of defects in the BT lattice. Adding both lanthanum and manganese in the structure led to the appearance of many more irregularities in ion packaging and stabilization of the pseudo-cubic structure $[10,11] . \mathrm{La}^{3+}$ substitutes a $\mathrm{Ba}$ ion in the barium titanate lattice and

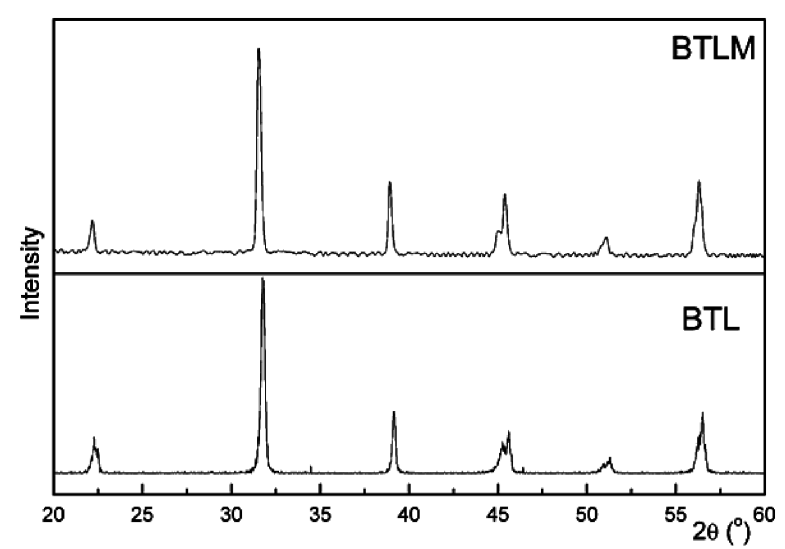

Fig. 1. X-ray diffractograms of BTL and BTLM samples sintered at $1300{ }^{\circ} \mathrm{C} / 8 \mathrm{~h}$.

doping commonly induced the formation of defects such as vacancies $\mathrm{V}_{\mathrm{Ti}}$ and $\mathrm{V}_{\mathrm{O}}$ and possibly $\mathrm{V}_{\mathrm{Ba}}$ in low concentrations [10]. It was expected that $\mathrm{La}^{3+}$ as a smaller ion would stabilize the cubic structure as predicted by Goldschmidt's tolerance factor. Doping with manganese is rather complex due to the tendency of $\mathrm{Mn}$ to change valence. It was proposed that $\mathrm{Mn}$ ions with the valence $2+, 3+$, and $4+$ partly replace $\mathrm{Ti}^{4+}$ ions [4] in the BT lattice. Some authors stated that substitution of $\mathrm{Ti}^{4+}$ with $\mathrm{Mn}^{2+}$ or $\mathrm{Mn}^{4+}$ can occur without any defect formation or with formation of one oxygen vacancy $\mathrm{V}$ " $\mathrm{O}$. Oxygen vacancy generation can also be noticed during sintering where oxygen loss can be observed [5]. Formation of donor-acceptor complexes, such as $2\left[\mathrm{LaBa}^{\bullet}\right]-$ $\left[\mathrm{MnTi}^{\prime \prime}\right]$ is also quite possible [7]. These changes of crystal structure can influence the dielectric spectrum of this material.

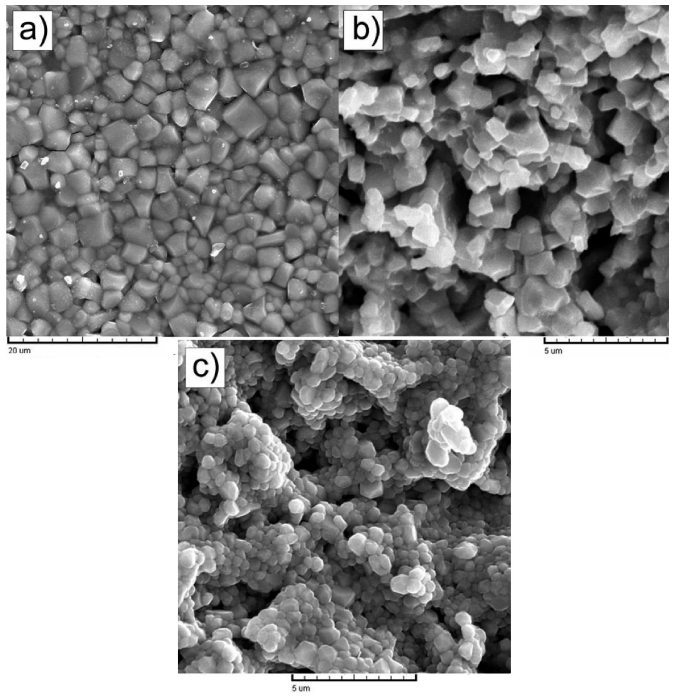

Fig. 2. Micrographs of barium titanate specimens sintered at $1300^{\circ} \mathrm{C}$ for $8 \mathrm{~h}$ : (a) BT, (b) BTL, and (c) BTLM. 
SEM micrographs showed a fine grained microstructure in both ceramics with a uniform grain size distribution and high percentage of porosity (Fig. 2b and c). Different authors have found high porosity in BT samples doped with lanthanum prepared by various methods, as well [12]. The density of both materials was around $85 \%$. It was observed that lanthanum inhibits grain growth in comparison with pure barium titanate (grain size $\approx 2.5 \mu \mathrm{m}$, density $92 \%$ ) prepared by the same chemical method (Fig. $2 \mathrm{a}$ ). The grain size was $\approx 1-0.7 \mu \mathrm{m}$ for the BTL samples and $\approx 0.5 \mu \mathrm{m}$ for the BTLM ceramics, indicating the influence of manganese on the further decrease of grains. The obtained grain size was much smaller than that obtained for a similar composition of BT ceramics $(1-4 \mu \mathrm{m})$ prepared by a solid-state reaction [12]. A more homogeneous microstructure with a uniform grain size distribution was formed in the BTLM doped samples. This was also noticed by other authors, where with the increase of $\mathrm{Mn}$ content the microstructure became more homogeneous [13]. Mn segregation at grain boundaries and therefore inhibition of grain growth is also possible. According to the obtained microstructure, it was expected that the microstructure formed in BTLM ceramics could enable better dielectric properties of the material.

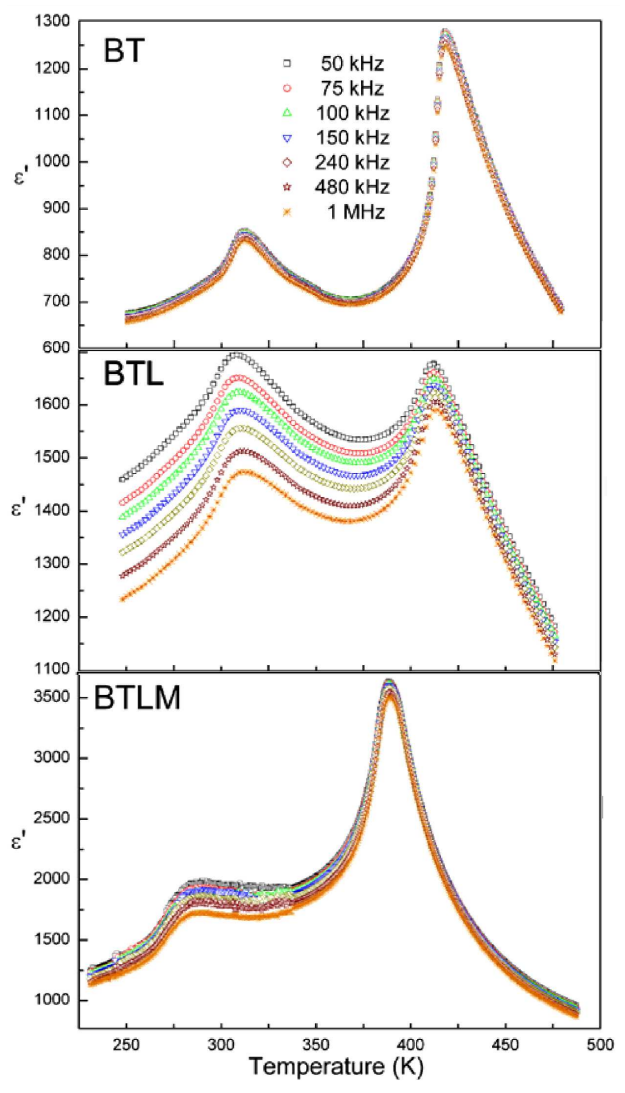

Fig. 3. Temperature dependence of dielectric constant in the frequency range $50 \mathrm{kHz}-1 \mathrm{MHz}$ for (top) BT, (middle) BTL, and (bottom) BTLM ceramics.
The phase transitions that correspond to $T_{\mathrm{C}-\mathrm{T}}$ (cubic-tetragonal) and $T_{\mathrm{T}-\mathrm{O}}$ (tetragonal-orthorhombic) (Fig. 3) in the temperature range from $223-448 \mathrm{~K}$ were noticed. The phase transition $T_{\mathrm{O}-\mathrm{R}}$ (orthorhombic-rhombohedral) was not identified because it is below the temperature range of our measurements [14].

\section{TABLE}

Transition temperatures, dielectric permittivity at room and Curie temperature, dielectric losses and diffuseness factor for the BT, BTL and BTLM samples at $100 \mathrm{kHz}$.

\begin{tabular}{c|c|c|c|c|c|c}
\hline \hline Sample & $\begin{array}{c}T_{\mathrm{C}-\mathrm{T}} \\
{\left[{ }^{\circ} \mathrm{C}\right]}\end{array}$ & $\begin{array}{c}T_{\mathrm{T}-\mathrm{O}} \\
{\left[{ }^{\circ} \mathrm{C}\right]}\end{array}$ & $\varepsilon^{\prime}\left(T_{\text {room }}\right)$ & $\varepsilon^{\prime}\left(T_{\mathrm{C}}\right)$ & $\tan \delta$ & $\gamma$ \\
\hline BT & 120 & 14 & 805 & 1280 & 0.013 & 1.18 \\
BTL & 114 & 9 & 1595 & 1655 & 0.08 & 1.25 \\
BTLM & 115 & 12 & 1902 & 3609 & 0.06 & 1.15
\end{tabular}

The position of the $T_{\mathrm{C}-\mathrm{T}}$ peak in doped ceramics was shifted to lower temperatures in comparison with $120^{\circ} \mathrm{C}$ found for pure BT (Table). Literature data also confirmed that addition of lanthanum as a dopant in the barium titanate lattice could cause a shift of the $T_{\mathrm{C}-\mathrm{T}}$ phase transition to lower temperatures $[12,14]$. Shifting of phase transitions is commonly connected with a grain size change and in the investigated case it is noticeable that lanthanum and manganese reduced the grain size of ceramics (SEM micrographs). A possible explanation of these phenomena can also be found in defect chemistry. A lanthanum ion with a radius $r\left(\mathrm{La}^{3+}\right)=1.17 \AA$ changes a barium ion with $r\left(\mathrm{Ba}^{2+}\right)=1.49 \AA$ in a barium titanate lattice [15].

Two types of compensation mechanisms are possible for added concentrations of lanthanum. First, lanthanum donor doping could occur via an electronic compensation mechanism where electrons are formed

$$
\mathrm{Ba}_{\mathrm{Ba}} \rightarrow \mathrm{LaBa}+\mathrm{e}^{\prime} .
$$

Next, the ionic, titanium-vacancy compensation mechanism is also possible for concentrations of La below $0.3 \mathrm{~mol} . \%$ and it is presented by

$$
4 \mathrm{Ba}_{\mathrm{Ba}}+\mathrm{Ti}_{\mathrm{Ti}} \rightarrow 4 \mathrm{La}_{\mathrm{Ba}}+\mathrm{V}_{\mathrm{Ti}}^{\prime \prime \prime \prime} \text {. }
$$

The presence of $\mathrm{La}$ on a $\mathrm{Ba}$ site makes the tetragonal structure weaker and possible generation of $\mathrm{Ti}$ vacancies $\left(\mathrm{V}_{\mathrm{Ti}}\right)$ destroys $\mathrm{Ti}-\mathrm{O}-\mathrm{Ti}$ linkages. This occurrence leads to lowering of $T_{\mathrm{C}}$. On the other hand, manganese in BT can exist in three valence states $r\left(\mathrm{Mn}^{2+}\right)=0.80 \AA$, $r\left(\mathrm{Mn}^{3+}\right)=0.72 \AA$, and $r\left(\mathrm{Mn}^{4+}\right)=0.67 \AA$ and it commonly substitutes $\mathrm{Ti}^{4+}$ due to its small ionic radius $r\left(\mathrm{Ti}^{4+}\right)=0.75 \AA[15,16]$. Some authors proposed the model where moving of manganese ions is always carried on $\mathrm{Ti}-\mathrm{Ti}$ chains in the BT structure. The presence of $\mathrm{Mn}$ on a Ti site also leads to disrupting of Ti-O-Ti linkages responsible for ferroelectricity and hence lowering of $T_{\mathrm{C}}$. Literature data have shown that sintering in air at high temperatures could induce the formation of oxygen vacancies and in some cases lead to the appearance of semiconducting behaviour [17]. The formation of oxygen vacancies and conduction electrons can occur according to the reaction 
$2 \mathrm{O}_{\mathrm{O}} \rightarrow \mathrm{O}_{2}+2 \mathrm{~V}_{\mathrm{O}}^{\prime \prime}+4 \mathrm{e}^{\prime}$.

The loss of oxygen during sintering could enable stabilization of acceptor $\mathrm{Mn}^{2+}$ ions and in combination with formed oxygen vacancies shift the $T_{\mathrm{C}}$. On the other hand, during cooling, stabilization of $\mathrm{Mn}^{4+}$ or $\mathrm{Mn}^{3+}$ is possible with a decrease of $\mathrm{V}_{\mathrm{O}}^{\prime \prime}$ concentration and therefore again a Curie point shift. If stable donor-acceptor complexes $2\left[\mathrm{La}_{\mathrm{Ba}}^{\cdot}\right]-\left[\mathrm{Mn}_{\mathrm{Ti}}^{\prime \prime}\right]$ are formed, the $\mathrm{Mn}^{2+}$ ion can no longer be oxidized into $\mathrm{Mn}^{3+}$ or $\mathrm{Mn}^{4+}$ [7].

Phase transitions $T_{\mathrm{C}-\mathrm{T}}$ for BTL and BTLM ceramics were located at almost the same temperature. This could indicate that lanthanum influenced shifting of the Curie point but added concentrations of manganese did not affect its additional movement. The temperature positions of phase transitions did not change with frequency but a certain frequency dispersion of dielectric permittivity was noticed especially for BTL.

The characteristic $T_{\mathrm{C}-\mathrm{T}}$ peak for pure barium titanate was sharp (Fig. 3a). The shape of this phase transition in doped samples was found to be broader, indicating the effect of dopants on dielectric properties. This is especially evident for BTL ceramics. A certain degree of phase transition diffuseness can be noticed from the presented diagrams. Therefore, the modified Curie-Weiss law was used to determine the degree of diffuseness of the barium titanate phase transition. The modified CurieWeiss law was presented by the following equation:

$$
1 / \varepsilon-1 / \varepsilon_{\max }=\left(T-T_{\max }\right)^{\gamma} / C,
$$

where $\gamma$ and $C$ are modified constants, $\varepsilon_{\max }$ is the dielectric permittivity maximum at the transition temperature $T_{\max }\left(T_{\mathrm{C}-\mathrm{T}}\right)$ [18]. The constant $\gamma$ gives information about the character of the phase transition and it varies between 1 in the case of a classical ferroelectric and 2 for relaxor materials. The constant $\gamma$ represents the slope of the graph between $\ln \left(1 / \varepsilon-1 / \varepsilon_{\max }\right)$ and $\ln \left(T-T_{\max }\right)$ and is an indicator of the diffuseness or disorder of the phase transition (Fig. 4). The results obtained for diffuseness for BT, BTL and BTLM ceramics are presented in Table. It can be noticed that lanthanum increased the

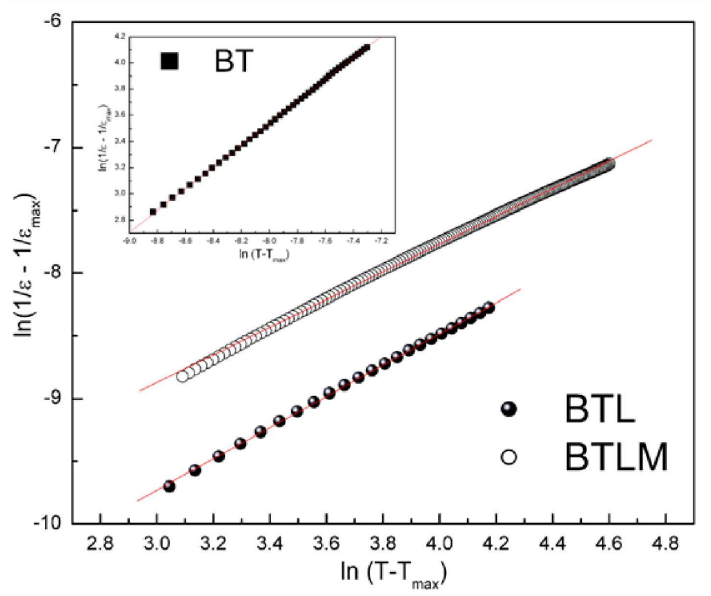

Fig. 4. $\ln \left(1 / \varepsilon-1 / \varepsilon_{\max }\right)$ and $\ln \left(T-T_{\max }\right)$ plots for BT, BTL, and BTLM ceramics at $100 \mathrm{kHz}$. diffuseness of the barium titanate phase transition but adding of manganese caused its decrease.

Dielectric permittivity values have also changed with dopant addition. In pure BT, the dielectric permittivity was 805 at room temperature and 1280 at the Curie temperature. The results given in Table indicate a slight increase in dielectric permittivity with lanthanum addition and a further increase with adding of manganese. The existence of smaller grains in doped samples could be a possible reason for the dielectric constant increase [19]. This is in agreement with the study performed by Arlt et al. [20] where BT samples with a grain size $\approx 0.5 \mu \mathrm{m}$ possessed the highest dielectric constant value. These authors consider that a plausible explanation is based on the size of the ferroelectric domain structure. When the grain size decreases, the size of the ferroelectric $90^{\circ}$ domains will become smaller and hence the material will have more but smaller domains.

Since the permittivity of BT ceramics is considered to be the sum of a volume contribution and domain wall contribution, the increase in permittivity of fine-grained BT can be explained primarily by a large number of $90^{\circ}$ domain walls per unit volume [20]. It can be assumed that very low concentrations (up to $0.6 \mathrm{~mol} . \%$ ) of lanthanum are completely incorporated in the BT lattice as proposed by other authors [19], influencing the dielectric constant increase. The dielectric loss factor showed lower values for BTLM ceramics in comparison with BTL (Table). These results are in agreement with the fact that manganese is usually added with donor dopants in order to reduce the dissipation factor $[7,21]$.

Regarding electrical resistivity, in pure barium titanate prepared by the same processing methods, the electrical resistivity was $>10^{8} \Omega \mathrm{cm}$, indicating BT insulating behaviour. The addition of dopants into barium titanate usually leads to the appearance of semiconducting behaviour and in some cases appearance of the positive temperature coefficient of resistivity (PTCR) effect.

The resistivity of a material depends on transport processes that occur in grains and grain boundaries. Free carrier motion is often influenced by the grain size and grain size distribution, secondary phases, nature and place of impurities, crystal lattice disorder, defects, etc. [22-24]. Both doped ceramics (BTL and BTLM) were bluish, indicating the formation of $n$-type semiconducting materials $[25,26]$. Electrical resistivity of the BTL ceramics at room temperature was $1.3 \times 10^{5} \Omega \mathrm{cm}$ and it was lower than $1.1 \times 10^{7} \Omega \mathrm{cm}$ obtained for the BTLM ceramics.

Adding of lanthanum and manganese led to a grain size reduction and formation of defects $\left(\mathrm{V}_{\mathrm{Ti}}\right.$ and $\mathrm{V}_{\mathrm{O}}$ vacancies, as well as $\mathrm{La} / \mathrm{Mn}$ defect complexes $[7,10])$. First, doping only with lanthanum induced the formation of free electrons and possibly $\mathrm{V}_{\mathrm{Ti}}$ and $\mathrm{V}_{\mathrm{O}}$ that decreased the resistivity of the material. In BTLM ceramics manganese acted as an acceptor on Ti-sites and it was believed to segregate at the grain boundaries. 


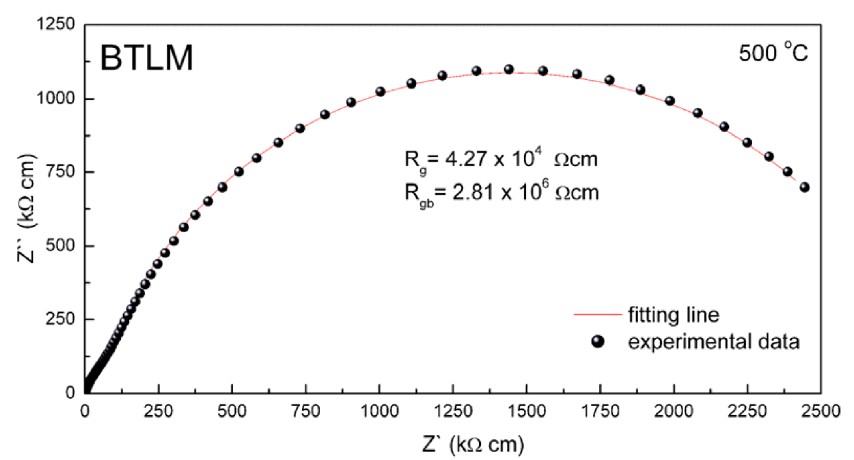

Fig. 5. The complex impedance plane plot $\left(Z^{\prime \prime}-Z^{\prime}\right)$ at $500{ }^{\circ} \mathrm{C}$ for BTLM ceramic.

In order to see the contribution of grain and grain boundary resistivity of the BTLM ceramic, an impedance spectrum at $500{ }^{\circ} \mathrm{C}$ is given in Fig. 5. Looking very closely, one depressed semicircle indicates possible overlapping of two semicircular arcs. The low frequency semicircle corresponds to the grain boundary contribution and the high frequency semicircular arc is attributed to the grain contribution. The equivalent circuit consisted of two parallel RC elements connected in series and the $Z$-view fitting software was used to evaluate the values of $R_{\mathrm{g}}$ (grain resistivity) and $R_{\mathrm{gb}}$ (grain boundary resistivity). The chosen equivalent circuit was indicated as suitable for the investigated ceramics due to very fine fitting of experimental results. The grain boundary resistivity was found to be much higher than grain resistivity.

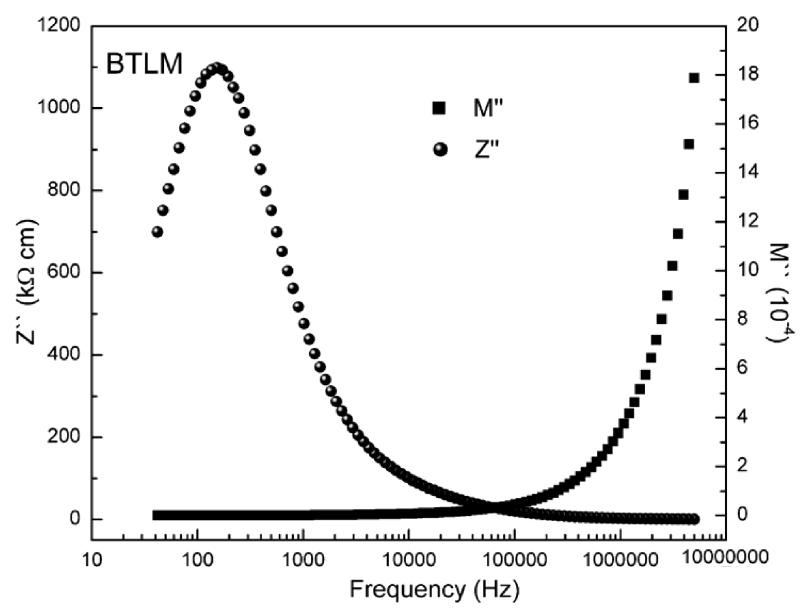

Fig. 6. Variation of imaginary parts of impedance $\left(Z^{\prime \prime}\right)$ and modulus $\left(M^{\prime \prime}\right)$ with frequency at $500{ }^{\circ} \mathrm{C}$ for BTLM ceramic.

In order to complement and verify the data obtained by fitting of the impedance complex plane plot $\left(Z^{\prime \prime}-Z^{\prime}\right)$ the $Z^{\prime \prime}-f$ and $M^{\prime \prime}-f$ spectroscopic plots were used for the extraction of grain and grain boundary resistivities of the BTLM material (Fig. 6) [27, 28]. $Z^{\prime \prime}$ spectra dominated by the grain boundary response and the Debye-like peak can be used to estimate $R_{\mathrm{gb}}$ and $C_{\mathrm{gb}}$. The obtained $R_{\mathrm{gb}}=2.3 \times 10^{6} \Omega \mathrm{cm}$ and $C_{\mathrm{gb}}=0.5 \mathrm{nF}$ are values similar to those obtained from the complex impedance spectrum (Fig. 5) confirming the high contribution of grain boundary resistivity to the total resistivity of the material. $M^{\prime \prime}$ spectra are dominated by the grain response and $R_{\mathrm{g}}$ and $C_{\mathrm{g}}$ could be calculated from it. Since $M^{\prime \prime}$ spectra did not show a Debye-like peak for the impedance measurements at $500{ }^{\circ} \mathrm{C}$, these results were not obtained.

The resistivity increased with manganese addition and it can be attributed to a drop of carrier concentration since manganese could act as an electron trap at the grain boundaries. On the other hand, $\mathrm{Mn}^{3+}$ and $\mathrm{Mn}^{4+}$ are more reducible than $\mathrm{Ti}^{4+}$ and therefore electrons were trapped at these sites. The manganese concentration was very low and the hopping motion of trapped electrons from one Mn site to another was almost impossible. Thus, the conduction electrons were effectively localized at these Mn sites, which resulted in a drop of the carrier concentration and increase of the BTLM ceramics resistivity. In order to see the appearance of the PTCR effect measurements of resistivity vs. temperature are in the scope of future investigations.

\section{Conclusion}

Barium titanate doped with La and co-doped with $\mathrm{La} / \mathrm{Mn}$ was prepared by a soft chemical method. A tetragonal structure was formed in both ceramics but lattice parameters for the BTLM ceramics showed stabilization of the pseudo-cubic structure due to formation of more irregularities in the BT lattice. A grain size reduction in doped samples was noticed in comparison with pure BT ceramics $(\approx 2.5 \mu \mathrm{m})$. The phase transitions in doped ceramics were shifted to lower temperatures showing the well known influence of dopants on dielectric spectra of barium titanate. The dielectric permittivity increased slightly with lanthanum addition and furthermore with adding of manganese. Co-doping with La/Mn increased the dielectric constant and made the transitions more prominent. Therefore, the diffuseness or disorder of the phase transition in the BTL was higher than in the BTLM, suggesting stabilization of the classical ferroelectric shape of the phase transition with manganese addition. The resistivity of the BTLM ceramics at room and the Curie temperature was higher than for the BTL ceramics, showing the influence of doping with manganese on electron carrier decrease. Impedance analysis proved the high contribution of the grain boundary resistivity in the total resistivity of BTLM ceramics, indicating possible segregation of manganese at grain boundaries.

Future work may lead to the development of novel materials with higher dielectric permittivity and a homogeneous but porous structure that can possibly find application in humidity sensors.

\section{Acknowledgments}

The authors gratefully acknowledge the Ministry of Education, Science and Technological Development of 
the Republic of Serbia for the financial support of this work (project III45021) and COST MP0904.

\section{References}

[1] B.D. Stojanović, in: Proc. Ninth World Round Table Conf. on Sintering, Eds. B.D. Stojanović, V.V. Skorokhod, M.V. Nikolic, Kluwer Academic/Plenum Publishers, New York 1999, p. 367.

[2] D. Gulwade, P. Gopalan, Solid State Commun. 146, 340 (2008).

[3] M.M. Vijatović, B.D. Stojanović, J.D. Bobic, T. Ramoska, P. Bowen, Ceram. Int. 36, 1817 (2010).

[4] X. Wang, M. Gu, B. Yang, S. Zhu, W. Cao, Microelectron. Eng. 66, 855 (2003).

[5] H. Moriwake, C. Fisher, A. Kuwabara, Jpn. J. Appl. Phys. 49, 09MC01 (2010).

[6] R. Schwartz, B. Wechsler, Phys. Rev. B 48, 7057 (1993).

[7] K. Albertsen, D. Hennings, O. Steigelmann, J. Electroceram. 2, 193 (1998).

[8] M.P. Pechini, N. Adams, United States Patent No. 3, 697, 697 (1967).

[9] L. Ramajo, R. Parra, M. Reboredo, M. Zaghete, M. Castro, Mater. Chem. Phys. 107, 110 (2008).

[10] F.D. Morrison, D.C. Sinclair, A.R. West, J. Appl. Phys. 86, 6355 (1999).

[11] M.M. Vijatović Petrović, J.D. Bobic, T. Ramoska, J. Banys, B.D. Stojanović, Mater. Char. 62, 1000 (2011).

[12] O. Parkash, D. Kumar, R.K. Dwivedi, K.K. Srivastava, P. Singh, S. Singh, J. Mater. Sci. 42, 5490 (2007).

[13] C.-J. Thing, C.-J. Peng, H.-Y. Lu, S.-T. Wu, J. Am. Ceram. Soc. 73, 329 (1990).
[14] S.M. Bobade, D.D. Gulwade, A.R. Kulkarni, P. Gopalan, J. Appl. Phys. 97, 074105 (2005).

[15] http://en.wikipedia.org/wiki/Ionic_radius .

[16] B.D. Stojanović, M.A. Zaghete, C.R. Foschini, F.O.S. Vieira, J.A. Varela, Ferroelectrics 270, 15 (2002).

[17] S. Urek, M. Drofenik, D. Makovec, J. Mater. Sci. 35, 895 (2000).

[18] S. Anwar, P.R. Sagdeo, N.P. Lalla, Solid State Comm. 138, 331 (2006).

[19] M.S. Castro, W. Salgueiro, A. Somoza, J. Phys. Chem. Solids 68, 1315 (2007).

[20] G. Arlt, D. Hennings, G. de With, J. Appl. Phys. 58, 1619 (1985).

[21] V. Paunović, V. Mitic, V. Pavlović, M. Miljković, Lj. Zivković, Proc. Appl. Ceram. 4, 253 (2010).

[22] B. Huybrechts, K. Ishizaki, M. Takata, J. Mater. Sci. 30, 2463 (1995).

[23] F.D. Morrison, D.C. Sinclair, A.R. West, J. Am. Ceram. Soc. 84, 531 (2001).

[24] F.D. Morrison, D.C. Sinclair, A.R. West, Int. J. Inorg. Mater. 3, 1205 (2001).

[25] M.E.V. Costa, P.Q. Mantas, J. Eur. Ceram. Soc. 19, 1077 (1999).

[26] A.F. Shimanskij, M. Drofenik, D. Kolar, J. Mater. Sci. 29, 6301 (1994).

[27] N. Hirose, A.R. West, J. Am. Ceram. Soc. 79, 1633 (1996).

[28] A. Shukla, R.N.P. Choudhary, A.K. Thakur, D.K. Pradhan, Physica B 405, 99 (2010). 